Revista de la Escuela de Ciencias de la Educación, año 13, nRo. 12, vol. 2, JUlio a diciembre de 2017. Páginas 35-48. ISSN 1851-6297. ISSN 2362-3349 (EN LINEA). APRENDER HACIENDO. REFLEXIONES EN TORNO A LA FORMACIÓN COMO ANTROpólogos. Stella Maris Garcia, Griselda laura Aragón y luciana Pérez Clavero

\title{
APRENDER HACIENDO. REFLEXIONES EN TORNO A LA FORMACIÓN COMO ANTROPÓLOGOS
}

\author{
Por Stella Maris García * \\ Universidad Nacional de La Plata \\ elitagarciacitybell@gmail.com \\ Griselda Laura Aragón * \\ Universidad Nacional de La Plata \\ glauraaragon@gmail.com \\ Luciana Pérez Clavero ${ }^{* * *}$ \\ Universidad Nacional de La Plata \\ lulaprez@hotmail.com
}

Recibido: 30/09/2016 Aceptado: 20/01/2016

\footnotetext{
Profesora Adjunta de la Cátedra Antropología Sociocultural I. Laboratorio de Investigaciones en Antropología Social (LIAS)- Facultad de Ciencias Naturales y Museo (FCNYM). Universidad Nacional de la Plata (UNLP). Investigadora Categoría "III" U.N.L.P. Línea de Investigación: Antropología y Educación. Prácticas Escolares. El Poder en la escuela. Educación Escolar Indígena. Procesos educativos en perspectiva histórica.

* Licenciada en Antropología (FCNyM - UNLP) y Prof. En Docencia Superior (UTN FRA INSPT), se desempeña actualmente como colaboradora en el Laboratorio de Investigaciones en Antropología Social (LIAS - FCNYM / UNLP), asesora de la Defensoría del Pueblo de la Provincia de Buenos Aires y profesora de nivel secundario. Trabaja temáticas vinculadas a pueblos indígenas e identidad, patrimonio cultural, imaginarios urbanos y demandas territoriales.

*** Licenciada en Antropología de la Facultad de Ciencias Naturales y Museo. Cursando la carrera de Doctorado en Antropología en la Facultad de Filosofía y Letras, UBA. Investigadora colaboradora en el Laboratorio de Investigación en Antropología Social (LIASFCNyM- UNLP) bajo la dirección de la Lic. Stella Maris García. Se desempeñó como auxiliar Docente Alumna Ad Honorem Cátedra Antropología Sociocultural I. Laboratorio de Investigaciones en Antropología Social (LIAS) - FCNYM/ UNLP. Actualmente participa como investigadora en la Sección de Etnohistoria en el Instituto de Ciencias Antropológicas (ICA- FFyL/UBA).
} 


\section{Resumen}

El presente trabajo da cuenta de cómo un viaje de campaña constituye una estrategia pedagógica que, además de producir conocimiento, permite que los participantes se visualicen como "personas" y futuros antropólogos sociales profesionales. Presentamos algunas reflexiones en torno a un hacer en la formación pedagógica de los futuros profesionales, desde un espacio curricular de tercer año de la carrera de Licenciatura en Antropología de la Facultad de Ciencias Naturales y Museo (FCNyM - UNLP) a partir de preguntarnos ¿Qué fundamenta la realización de un viaje de campaña en la cátedra Antropología Sociocultural I?. Nuestro planteo se centra en potenciar la búsqueda de estrategias didácticas que permitan el extrañamiento y contribuyan a ejercitar el acercamiento/distanciamiento a los fenómenos humanos que aparecen como obvios, comunes, adosados a la vida cotidiana y naturalizada su existencia.

Palabras clave: Antropología - Educación - Viaje de campaña - Persona Fenómeno humano.

\section{Abstract}

This paper shows how a campaign trip is a teaching strategy that besides producing knowledge, allow participants are displayed as 'persons' and future professional social anthropologists. We present some reflections around a do in the pedagogical training of future professionals, from a curricular space third year of the Bachelor in Anthropology from the Faculty of Natural Sciences and Museum (FCNyM - UNLP) from asking What based conducting a campaign trip in Sociocultural Anthropology professor I?. Our proposal focuses on strengthening the search for educational strategies to estrangement and contribute to exercise the approach / distancing human phenomena that appear as obvious, common, attached to everyday life and naturalized their existence.

Keywords: Anthropology - Education - Campaign trip - Person - Human phenomenon.

"Francamente, entonces me pareció, y me lo sigue pareciendo ahora, que la justificación del estudio de campo, al igual que la de cualquier actividad académica, no reside en la contribución a la colectividad sino en una satisfacción egoísta. Como la vida monástica, la investigación erudita no persigue sino la perfección de la propia alma" Nigel Barley. El antropólogo inocente. (1989, p. 20). 
Revista de la Escuela de Ciencias de la Educación, año 13, nRo. 12, vol. 2, JUlio a diciembre de 2017. Páginas 35-48. ISSN 1851-6297. ISSN 2362-3349 (EN LiNEA). APRENDER HACIENDO. REFLEXIONES EN TORNO A LA FORMACIÓN COMO ANTROpólogos. Stella Maris Garcia, Griselda laura Aragón y luciana Pérez Clavero

\section{Presentación}

El propósito de este trabajo es compartir algunas reflexiones en torno a un hacer en la formación de los futuros profesionales antropólogos, desde el espacio curricular de tercer año de la carrera universitaria de Licenciatura en Antropología, de la Facultad de Ciencias Naturales y Museo, Universidad Nacional de La Plata. Como antropólogas interpeladas por la afirmación de Barley (1989), centramos nuestro planteo en la necesidad de trazar lineamientos que faciliten a los estudiantes construir mirada en el hacer antropológico, generar experiencias donde se ponga el cuerpo y la palabra, se dimensione su condición de "persona", se cuestione el propio sentido dado a los objetos, las acciones y las relaciones, se considere al "otro humano" en su dimensión temporal y espacial, se coloque la materialidad del contexto y sus significados simbólicos en procesos socioeconómicos históricamente situados y siempre en movimiento. Subrayamos la noción de "persona" formulada por el antropólogo Radcliffe - Brown (1975, p.183) en la que enfatiza el carácter relacional de los sujetos dentro de la trama social. Así, las personas somos el resultado de la construcción relacional, colectiva y culturalmente determinados (Velázquez Galindo, 2012).

Apelamos al "viaje" como instancia para potenciar la búsqueda de estrategias pedagógicas que permitan el extrañamiento y contribuyan a ejercitar el acercamiento/distanciamiento a los "fenómenos humanos" (Berger-Luckmann, 1976, pp. 66-74) que aparecen como obvios, comunes, adosados a la vida cotidiana y de existencia naturalizada. La acreditación de viajes de campaña es condición formal en la carrera de Antropología para lograr obtener el título, sin embargo, recién en los últimos años se reglamentó su realización y se cuenta con partidas presupuestarias para llevarlos a cabo desde distintas cátedras, como experiencias pedagógicas planificadas. ¿Qué fundamenta la realización de un viaje de campaña en la cátedra Antropología Sociocultural I? Entendemos, siguiendo al antropólogo Esteban Krotz (1991), que "el viaje antropológico tiene usualmente un propósito claro y definido: a través de él se quiere conocer un determinado aspecto de la realidad sociocultural, una problemática, un sector poblacional, los habitantes de una región, un grupo social, una cultura o como se quiera decir" (1991, p. 54). En este sentido, el viaje antropológico se presenta como un escenario donde se cruzan alteridades e identidades dinámicas. Nos decidimos entonces, a plantear que el viaje de campaña constituye una estrategia pedagógica que, además de producir conocimiento sobre la zona visitada, permite que los participantes se visualicen en interacción reflexiva con otros, con sus propias perspectivas racistas (Menéndez, 1972), tanto con preguntas sobre usos, sentidos y valores como con curiosidades existenciales y preconceptos, pues se trata del proceso de construirse como profesionales antropólogos. 


\section{Antropología, una profesión 'rara y difusa'}

Resulta importante realizar la genealogía y contextualización de la disciplina y subrayar que desde hace unos años y en el marco de proyectos de investigación sobre los procesos educativos (1) pretendemos producir conocimiento y recuperar experiencias de valor formativo para los estudiantes, en este caso, de la disciplina. Colocamos a la Educación como una preocupación central en el horizonte político y sociocultural abordándola desde el campo disciplinar de la Antropología, de sus estructuras de significado y de sus aportes conceptuales para problematizar el espacio curricular en el que nos toca actuar. En la formación universitaria se recrean sesgos adquiridos en las trayectorias de escolarización lo que influye de diversos modos en el aprendizaje de los nuevos contenidos disciplinares y el necesario 'extrañamiento' ante el acontecer de la vida social que exige la perspectiva antropológica.

La Antropología es una disciplina científica que se desarrolla como tal en la Universidad Nacional de la Plata en la Facultad de Ciencias Naturales y Museo desde fines del siglo XIX. Hacia mediados del mismo siglo, durante el proceso de constitución de nuestro Estado Nación, el sistema educativo fue uno de los principales engranajes, a la vez que un medio para su consolidación. La Constitución Nacional de 1853 estableció el derecho a la educación como una responsabilidad atribuida a los gobiernos provinciales y en la provincia de Buenos Aires, tuvieron lugar las primeras experiencias educativas de este período de conformación, entre ellas la sanción de la Ley Provincial de Educación Común y la creación de establecimientos educativos. Hacia el año 1869, en tiempos de la presidencia de Domingo Faustino Sarmiento, se realizó el primer Censo Nacional cuyos resultados presentaron a la Argentina como un territorio rico en recursos naturales pero con una población escasa, atrasada tecnológicamente y carente de disposición al trabajo, al orden y la disciplina; según Sarmiento, caracterizada por su "amor a la ociosidad e incapacidad industrial, cuando la educación y las exigencias de una posición social no vienen a ponerle espuela y sacarla de su paso habitual" (1851, p.28). Para la concepción evolucionista de la época, el progreso y la civilización sólo serían posibles a través de la educación y del crecimiento demográfico a partir de la inmigración europea. Tal como quedará plasmado en la obra Facundo "la ciudad es el centro de la civilización argentina, española, europea; allí están los talleres de las artes, las tiendas del comercio, las escuelas y colegios, los juzgados, todo lo que caracteriza, en fin, a los pueblos cultos" (p. 29), hasta nuestro días, la dicotomía civilización/barbarie circula en el imaginario social, en ciertos espacios educativos y es el fundamento de ciertas políticas culturales.

La Argentina recientemente constituida en Estado Nación, se insertó en un mercado con una clara división internacional del trabajo, como productora de 
Revista de la Escuela de Ciencias de la Educación, año 13, nRo. 12, vol. 2, julio a diciembre de 2017. Páginas 35-48. ISSN 1851-6297. ISSN 2362-3349 (EN LiNEA). APRENDER HACIENDO. REFLEXIONES EN TORNO A LA FORMACIÓN COMO ANTROpólogos. Stella Maris Garcia, Griselda laura Aragón y Luciana Pérez Clavero

materias primas. El modelo de acumulación capitalista agroexportador de la época se sentó sobre modos de relación social de bases coloniales y fue la continuación de la situación colonial nacida hacia el siglo XVI producto de la llamada "Conquista de América". La situación colonial ha sido caracterizada por George Balandier (1973) como el desarrollo de tres empresas: material, político administrativa e ideológica; que implican la dominación y expansión de un grupo minoritario numéricamente sobre los territorios, autoridades locales, sistemas económicos, políticos y de creencias de una mayoría. En 1884, durante la presidencia del General Roca, se aprobó la Ley Nacional 1420 de educación pública, común, gratuita, gradual y laica a cargo del Estado. En dicho contexto, las concepciones de "civilización" de la sociedad argentina, se erigían en detrimento del "salvajismo" y la "barbarie" teniendo a la educación como piedra basal de la que las elites dominantes supieron servirse para educar y "civilizar" a la población y para avanzar sobre pueblos indígenas "salvajes" y territorios "desiertos", a través por ejemplo, de la llamada "Conquista del Desierto". La civilización y el deber de civilizar en la época, por parte de los grupos minoritarios dominantes, se fundaron en la creencia de la superioridad del conocimiento científico (García et. al., 2009).

Acorde a la concepción evolucionista de la época, los orígenes de la institucionalización del Museo de Ciencias Naturales (junio de 1884), tuvieron como uno de los ejes organizadores de las colecciones, a lo humano como producto de la naturaleza, materializado con objetos y restos óseos y hasta con la presencia de personas "otras" (pertenecientes a diferentes pueblos indígenas) que 'justificaban' un paradigma científico hegemónico, basado en etapas evolutivas. Desde 1906 y a lo largo del siglo XX en un desarrollo histórico, dialéctico y desigual (Colman, 1978) respecto a los centros académicos del norte y del resto de Latinoamérica, se imprimieron particularidades al desarrollo de la antropología local. Conceptualizada como una materia del campo de las Ciencias Naturales, que se fue configurando en el primer Plan de Estudios aprobado para el Instituto Superior del Museo (Ottenheimer, 2008), buscaba que los educandos se formaran como naturalistas, que conocieran todos los campos de las ciencias naturales y se movieran con igual soltura en el dominio de la piedra (geología), de la planta (botánica), del animal (zoología), del resto fósil (paleontología) o del artefacto histórico (antropología), tal como lo reseña Teruggi (1988).

A lo largo del siglo XX las características de los investigadores, sus influencias formativas y las disponibilidades materiales para la ejecución de investigaciones de diversos alcances fue consolidándose (Soprano, 2006), y en 1958 se implementó la carrera de Antropología al estilo de otros centros académicos (Teves et. al., 2008). Sin embargo, recién hacia fines de 1965, y atendiendo a la existencia de una cátedra de Antropología Cultural en la Universidad Nacional del Litoral (Garlbusky, 2003), comenzó a organizarse la 
primera cátedra de Antropología Social en la formación de los antropólogos locales. Las tensiones socio históricas de la época y teórico metodológicas del ámbito académico, inauguraron un período de cuestionamientos a las clásicas dicotomías naturaleza/cultura, individuo/sociedad, objetividad/subjetividad, infraestructura/superestructura dando lugar al Plan de Estudios de 1968 donde fue reconocida la Antropología Social como orientación junto a la Arqueología y la Antropología Biológica en la formación disciplinar de la Facultad de Ciencias Naturales y Museo. La carrera cerró la inscripción durante los años de la dictadura militar de la década de 1970 y se articuló con la de biología según un siniestro plan 1978-79 donde no figuraba la Antropología Social ni aún como asignatura. En 1985 el claustro de profesores y el de estudiantes consensuaron un nuevo plan de estudios que aún continúa vigente y que incluye dos espacios curriculares con el nombre de Antropología Sociocultural I y II para tercer y cuarto año respectivamente.

En la actualidad, desde la materia Antropología Sociocultural I (2) planteamos como objetivo general lograr que los estudiantes se introduzcan en el conocimiento de las herramientas teórico-metodológicas desarrolladas en el seno de lo que se ha dado en llamar Antropología Social y/o Cultural; las problemáticas abordadas y/o factibles de ser abordadas en el proceso de la producción de conocimiento sobre el fenómeno humano en su diversidad y en las desigualdades sociales que lo encuadran, según tiempos históricos y espacios territoriales. La relación de los grupos humanos entre sí y entre ellos y el ambiente para comprender la dimensión de lo humano como un nivel de organización particular, la articulación dialéctica de los aspectos biológicos, aspectos psicológicos y aspectos socioculturales y la reflexión y análisis de los grupos humanos en sus dimensiones económicas, políticas, étnicas, parentales, religiosas. Cumplimentar estos objetivos no solo requiere de lectura de bibliografía general y/o específica para incorporar las conceptualizaciones y preguntas que 'distinguen' la mirada disciplinar sino de argüir estrategias pedagógicas - didácticas que apunten a que docentes y alumnos se interroguen a sí mismos y a lo que los rodea. Ese diálogo da cuenta del movimiento, es decir, de la lógica dialéctica que define a la vida humana y no humana, en su articulación con la naturaleza.

El ser humano nace, crece, vive y se desarrolla en sociedad, en un mundo sociocultural, en un espacio y un tiempo determinados. Dicho mundo sociocultural, se entiende en términos de Mauss (2009) como un "fenómeno social total" constituido por distintas dimensiones que se afectan mutuamente. Uno de los aspectos (no manifiestos) de este fenómeno es el "conocimiento". Y aquí nos preguntamos cómo científicos sociales ¿Cómo podemos conocer científicamente el fenómeno humano? ¿Cómo podemos construir conocimiento en torno al mismo? Consideramos, siguiendo a Berger y Luckman (1976) que los sujetos construyen socialmente la realidad a partir de procesos de socialización. En una primera instancia ese proceso comporta secuencias de 
Revista de la Escuela de Ciencias de la Educación, año 13, nRo. 12, vol. 2, julio a diciembre de 2017. Páginas 35-48. ISSN 1851-6297. ISSN 2362-3349 (EN LiNEA). APRENDER HACIENDO. REFLEXIONES EN TORNO A LA FORMACIÓN COMO ANTROpólogos. Stella Maris García, Griselda laura Aragón y Luciana Pérez Clavero

aprendizaje socialmente definidas: "A la edad A el niño debe aprender $X$, y a la edad B debe aprender Y, y así sucesivamente". Así a medida que el niño va creciendo, se genera un "acopio de conocimiento"; adquiere conocimientos de su entorno y las relaciones sociales se van complejizando. Luego se internalizan "submundos" institucionales o basados sobre instituciones, estando su alcance y su carácter determinados por la complejidad de la división del trabajo y la distribución social del conocimiento. Junto con este proceso se adquieren vocabularios específicos de "roles". En el plano educativo, y en el contexto de realización de un viaje de campaña de Antropología Social, cabe preguntarnos quiénes juegan los roles de enseñar/aprender y qué implican dichos procesos de enseñanza-aprendizaje en el proceso de producción de conocimiento científico. Esto implica una práctica docente en la que como personas estamos involucrados aprendiendo.

\section{EI Viaje como experiencia de enseñanza-aprendizaje Escena 1. La Llegada.}

Sábado $11 \mathrm{hs}$. Bajamos del colectivo y nos recibió una mujer joven registrándonos con una cámara fotográfica y una sonrisa complaciente. Fuimos bajando y saludándola uno a uno los 42 , alumnos y docentes de las cátedras de Arqueología Americana I y Antropología Sociocultural I que habíamos subido la noche anterior a las $22 \mathrm{hs}$ en la Facultad de Ciencias Naturales y Museo de la Universidad Nacional de La Plata. Entramos por la amplia puerta del salón de usos múltiples -SUM- a lo que sería nuestro lugar para dormir, comer, higienizarnos, interactuar y aprender durante las siguientes 7 jornadas: la Escuela Hogar $\mathrm{N}^{\circ} 51$ de Colonia Josefa en el extremo este del Valle Medio del Río Negro, en la provincia homónima, Argentina. Rodeamos a aquella mujer que nos preguntaba ¿Cómo fue el viaje? ¡Seguramente están cansados! Pero pasen, bajen las cosas ¿Quieren conocer primero las instalaciones? Pasen, pasen... en comentarios casi al unísono se repetía una y otra vez iqué hermoso lugar! Iniciamos una recorrida desordenada atendiendo a sus relatos, que ampliaban las respuestas a nuestras indagaciones con explicaciones, anécdotas y exponiendo el actual problema del establecimiento, dos de los cuatro alumnos que hoy asisten a la escuela, egresan a fin de año. Al quedar solo dos alumnos ¿Cuál será el destino que las autoridades provinciales darán al edificio? Interrogante que hacía propio y compartía con los vecinos. Relató que se ocupó de nuclear una semana atrás, en un encuentro de más de 100 personas, a ex alumnos, autoridades locales y demás pobladores en el tradicional festejo de cumpleaños, en ocasión de los 113 años de existencia de Colonia Josefa. Con sólo dos meses en el cargo de directora y maestra del establecimiento depositaba en nuestro grupo el peso de una inquietud que la mantenía ocupada fundamentando 
proyectos que atendieran requerimientos de los vecinos como alternativas viables, ante los rumores de instalación de un penal en el lugar. Nuestra presencia, ajena a esas preocupaciones, encontraba las puertas abiertas de un espacio institucional que sintetiza la historia colonial de la región como un singular botón de muestra de la historia socioeconómica, cultural y política del país. ¡Qué gran desafío! Convivir durante siete días, treinta y cuatro estudiantes universitarios y sus ocho docentes, cuatro alumnos de primaria y cuatro maestros y personal de maestranza procurando llevar a cabo una experiencia de aprendizaje disciplinar; redimensionando los roles de cada uno ante las exigencias cotidianas; interpelando la forma de investigar e involucrarnos desde la antropología en la compleja y conflictiva realidad de Colonia Josefa y su escuela (3).

La primera escena, la llegada, implicó abrir la capacidad de imaginar, de crear, de mirar y ser mirados, de iniciar una búsqueda personal de sentidos y razones para poner el cuerpo en el proceso de aprender. En un encuentro inicial -a continuación de estar instalados en el lugar- propusimos reflexionar, analizar y dialogar cara a cara respecto de ¿Quiénes somos? ¿Qué hacemos aquí? ¿Qué compromiso ético implica? Organizados en tres grupos al azar instamos a armar historias asociadas a cada instancia (Viajar implica: 'Llegar' - 'Estar' - 'Partir') según les correspondiera, para luego ponerlas en común y acordar ¿Qué significa para este grupo hacer un viaje de campaña antropológico? Para lograr acuerdos a cumplimentar en la estadía.

\section{Escena 2. La Estadía.}

El edificio se nos imponía como un gran interrogante testigo de una historia escondida en sus paredes, en sus habitaciones con guardarropas y pilas de colchones, en sus rincones custodiados por altares con la Virgen de Lujan y Ceferino Namuncurá, con esculturas en honor a San Martin construidas en el año del Libertador y en honor al vecino que donó el terreno y su propia biblioteca (4), en objetos testigos de costumbres de otras épocas, en la actual tecnología de los artefactos, en los servicios sanitarios e instalaciones eléctricas, en los salones de clase completamente equipados con variedad de libros y materiales didácticos, en la cocina amplia con freezer, heladera y numerosa vajilla, en los eucaliptus centenarios, las arboledas de pinos, los cercos de plantas frutales, cañerías de riego distribuidas de modo subterráneo en antiguos sectores de plantación de hortalizas, variedad de pájaros, panales de abejas silvestres, martinetas, liebres, jabalíes con sus crías, dan vida plena al predio de poco más de una hectárea con juegos infantiles, mesas con asientos y una cancha de futbol que constituyeron el encuadre de nuestra estadía en Colonia Josefa.

La dinámica poblacional de la colonia comenzó en 1902 a instancias del 
Revista de la Escuela de Ciencias de la Educación, año 13, nRo. 12, vol. 2, julio a diciembre de 2017. Páginas 35-48. ISSN 1851-6297. ISSN 2362-3349 (EN LiNEA). APRENDER HACIENDO. REFLEXIONES EN TORNO A LA FORMACIÓN COMO ANTROpólogos. Stella Maris Garcia, Griselda laura Aragón y Luciana Pérez Clavero

Gobernador Mauricio Mayer, al permitir la instalación de 'colonos' dedicados a la ganadería ovina en los sectores más alejados del río y a la cosecha de alfalfa para comercializar su semilla, en los sectores de inundación por las crecientes anuales del Río Negro. En 1922, fue necesaria la creación de una escuela para atender a los numerosos niños/as de los grupos domésticos que llegaron a trabajar en la agricultura aprovechando la navegabilidad del río hasta la vera misma de esos territorios con salida directa al Atlántico, una estafeta postal y el único telégrafo de la región. A mitad del siglo $\mathrm{XX}$, las leyes de los gobiernos peronistas reorganizaron tensiones respecto a la tenencia de la tierra (5) y resguardaron la dependencia directa del régimen fluvial que garantizaba humedad suficiente para una diversidad agrícola-ganadera a escala pequeña y mediana. Un quiebre brutal a esta economía se estableció con la construcción de la represa Hidroeléctrica del Chocón que aminoró el cauce del rio y estableció una dependencia directa a sistemas artificiales de riego que implicaban onerosas inversiones que los propios colonos aun no logran realizar.

\section{Estrategias de Acción: Aprender/Enseñar/Aprender}

'Enseñar' a producir conocimiento desde la antropología social implica interpelar nuestra trayectoria de trabajo que se ensambla en una tradición disciplinar de nuestra institución y apela a la potencialidad de los jóvenes para la construcción responsable y crítica de su formación.

Entendemos, siguiendo a Litwin (2008, p. 29) que “...la enseñanza debería ser promotora del pensamiento apasionado -que incluye el deseo y la imaginación- para provocar una educación comprometida con la sociedad que a su vez dotará de significado la vida de los jóvenes". En este sentido, enseñar solo se entiende si partimos de aprender enseñando para comprender lo que implica una fuerte responsabilidad de acción. Por ello, nos negamos a considerar al viaje de campaña sólo como una práctica de ensayo o como un modo ejemplificador para la construcción de los saberes del oficio. Entendemos más bien que esta experiencia constituye un eslabón en el lento y complejo proceso de transformación en investigadores científicos sociales. Dicho proceso se nutre de rupturas sustantivas con el sentido común de la vida cotidiana (Bourdieu et. al., 1975) de quien aspira a convertirse en antropólogo y se encuadra en los procesos de búsqueda de los sentidos de las producciones y representaciones humanas para establecer relaciones e interpretarlas. Asímismo, requiere de comprender la relación hombre/naturaleza como una falsa dicotomía ya que es indispensable pero no suficiente analizar sus aspectos biológicos si no los anclamos en sus propios términos culturales.

En la estadía, ante tanto despliegue de objetos que guardaban secretos de años de silencio: fotos, libros, registros de asistencias, todos contenidos en una estructura de mampostería, nuestra estrategia requería lograr que se for- 
mulen preguntas, ya que, aún con pocas respuestas, esos objetos constituían la materialización del fenómeno humano sintetizado en ese lugar. Propusimos a los estudiantes que registraran y presentaran 'lo que veían' como cuestionamientos, como interpelaciones a esa realidad ¿Qué es esto que veo/escucho/ percibo? ¿Por qué/para qué está aquí? ¿Qué sentidos muestra/oculta su presencia? ¿Qué relaciones de poder o autoridad encubren? ¿Qué objetos aluden a creencias, cosmovisiones, religiosidad, sentimientos colectivos? ¿Dónde están ubicados? ¿Cómo se articulan con el ambiente y paisaje social de la región? ¿Quiénes, por qué y cuando habitaron este lugar? ¿Qué producen, distribuyen y consumen para sobrellevar su existencia? En el proceso de construcción de conocimiento se pone en juego una relación dialéctica entre el sujeto que investiga y el objeto/sujeto de investigación (Schaff, 1992) por lo que todo registro siempre tiene sentidos, puede ser uno o varios, compartidos o no por los sujetos involucrados. Desde la cátedra apelamos a la perspectiva teórica que fundamenta que la realidad tanto interna como externa a los sujetos se construye socialmente (Berger y Luckmann, 1976), construcción que se articula dialécticamente con los diversos actores como agentes sociales que experimentan el mundo. Las palabras, los gestos, los pensamientos, las trayectorias, los sentimientos, los procesos sociales que los atraviesan, etcétera, son la materia prima para la descripción y análisis, por lo que urge explicitar, poner en juego una sistematicidad y una lógica según los intereses propios y los que aparecen en la relación. En este sentido, el trabajo de campo se constituye en etnográfico en tanto el diseño de investigación se despliega mediante un proceso reflexivo que opera en todas sus instancias de desarrollo (Hammersley y Atkinson, 1994) y se activa desde el propio investigador hacia sí mismo, en relación con sus interlocutores y de estos entre sí -concepto de reflexividad- (Guber, 2001).

Tras media jornada de observación y registro en diversos soportes materiales, la definición de un problema de estudio antropológico fue la tarea que continuaría con las actividades del día. Para ello, los estudiantes se dividieron en pequeños grupos de no más de cuatro personas, y comenzaron su ejercicio de extrañamiento, de reconocimiento del otro y de ruptura con las estructuras previas para lograr responder sus preguntas. $Y$ así todo ese material registrado, todas esas historias narradas en relación con el entorno, comenzaron a ocupar el centro de la definición de las problemáticas y de objetivos que sería el paso a seguir del quehacer en el campo. A partir de allí, realizaron una búsqueda tentativa de estrategias metodológicas (6) que les permitieran aproximarse a la resolución de esas cuestiones desde un abordaje de la Antropología Social. La lectura del libro histórico de la escuela, registro de asistencias, fotos, las conversaciones con los vecinos y los habitantes de otras localidades aledañas a la Colonia, la interpretación del medio ambiente, la reconstrucción de genealogías perdidas por el tiempo, fueron las principales herramientas con las que los estudiantes se acercaron al encuentro con las posibles respuestas. 
Revista de la Escuela de Ciencias de la Educación, año 13, nRo. 12, vol. 2, julio a diciembre de 2017. Páginas 35-48. ISSN 1851-6297. ISSN 2362-3349 (EN LiNEA). APRENDER HACIENDO. REFLEXIONES EN TORNO A LA FORMACIÓN COMO ANTROpólogos. Stella Maris García, Griselda laura Aragón y Luciana Pérez Clavero

\section{Escena 3. La Partida.}

La noche del jueves 22 de Octubre, última velada que pasamos en Colonia Josefa, tuvo lugar el asado de despedida. De común acuerdo y casi sin tener que decirlo, profesores y alumnos coincidimos en que los tres docentes de la escuela así como nuestro cocinero, debían estar presentes en el asado como también las familias a las que pertenecen los alumnos. La mañana anterior llegaron los dos corderos que asó el cocinero de la escuela, quien fuera también nuestro compañero a lo largo de la estadía. Durante los preparativos para la cena nos organizamos en grupos de trabajo que cada uno fue integrando según su predisposición para afrontar las distintas tareas: juntar leña y prender el fuego, lavar las verduras y preparar las ensaladas, disponer las mesas, bancos y sillas en el S.U.M en dos hileras largas. En un pequeña mesa, ubicada en el centro de ambas hileras, se presentó el cordero en una gran asadera junto con las ensaladas, aderezos y el vino infaltable. Con una guitarra y dos cantantes, y el equipo de música cuando fallaba el repertorio, se generó en el pasillo de la escuela, un pequeño espacio de baile, enseñamos unos, otros aprendimos y casi todos recordamos la chacarera, el gato encadenado y el escondido. El asado y todas las instancias que involucró, recordó a los habitantes de la Colonia los festejos del 12 de octubre que marcan el aniversario del lugar, y que ritualmente congrega en la escuela a los vecinos, ex alumnos, ex docentes y no docentes y pobladores de los lugares aledaños como Pomona y Lamarque.

Encontrarnos con vecinos, con los niños, con los maestros y con nosotros mismos solo podía ser alrededor de un fuego y carne asándose, donde circulaban mensajes, anécdotas, historias, recetas para vegetarianos, el mate de mano en mano para ir sellando una experiencia de encuentros. No podíamos terminar nuestra estadía sin ese ritual, ese hecho social que pone en juego aquella trama de significados que se crean y resignifican en los símbolos que unen a los actores. Como afirma Barabas (...) "La gente se involucra en rituales individuales y colectivos porque acepta el trasfondo cultural que les subyace: mitos, valores, creencias, comportamientos, normas; y que los habilita como conductas compartidas" (...) (Barabas, 2006, p.180). Este ritual pone en acto una tradición cultural común que recrea el intercambio. Compartir en ese escenario, resultó ser una experiencia formativa y transformadora, en la que cada uno de nosotros como actores sociales, pusimos en juego nuestras propias representaciones de nuestros mundos simbólicos y la experiencia en este espacio extraño en un acto colectivo del rito. Docentes, estudiantes, universitarios, vecinos, personas, todos en un mismo tiempo y espacio rodeados de fuerte afectividad (Barabas, 2006), configurando un espacio de significaciones propias, que nos unían en un evento particular, pero que a su vez reforzaba rituales que históricamente se ponían en manifiesto en La Colonia (7). 
Revista de la Escuela de Ciencias de la Educación, año 13, nRo. 12, vol. 2, Julio a diciembre de 2017. PÁginas 35-48. ISSN 1851-6297. ISSN 2362-3349 (EN LiNEA). APRENDER HACIENDO. REFLEXIONES EN TORNO A LA FORMACIÓN COMO ANTROpólogos. Stella Maris García, Griselda laura Aragón y luciana Pérez Clavero

\section{Consideraciones finales}

La experiencia de "salir del aula" para ubicar el cuerpo en el campo, nos permitió no sólo poner en juego nuestras prácticas y universos simbólicos, sino también transformarlos dialécticamente con "el otro". En ese interjuego activamos el aprendizaje de conceptos, anclados en la experiencia del viaje y propuestos en el programa de la cátedra (distancia/acercamiento en la producción de conocimiento, construcción del objeto de investigación, y conceptos tales como paraje, colonia, pueblo, comunidad, grupo étnico, religiosidad, mito, ritual, grupo doméstico, parentesco, poder, economía, racismo, situación colonial, procesos productivos, de distribución y consumo, habitus/campo).

El aprendizaje acerca de que el conocimiento científico sobre el fenómeno humano, no es algo que se desarrolla unilateralmente, sino que puede ser el resultado de una experiencia conjunta (Tamagno et. al., 2005) entre docentes, estudiantes y los interlocutores que colaboraron afectuosamente con sus relatos, nos motivó a elaborar un producto final que registrara lo hecho. Motivación que, lejos de constituirse en "una satisfacción egoísta" en términos de la cita inicial (Barley, 1989) y, a fin de realizar una contribución como profesionales, se tradujo en la confección de un folleto, en el que brevemente queda explicitada la línea de tiempo de la Colonia, su historia, su dinámica, y su presente. Este folleto fue la materialización del trabajo en equipo llevado a cabo durante los días instalados en la escuela por los estudiantes, que laboriosamente fueron rastreando y combinando las historias envueltas en cada una de las narraciones, de las fotos, de los archivos, de los objetos que formaban parte del "universo Colonia Josefa".

Por este motivo sostenemos que la instancia de viaje de campaña que propone nuestra facultad (Menegas, et. al. 2003), no es simplemente una práctica. Es una experiencia formativa y transformadora, en la que se ponen en juego anclajes teóricos y cada uno de nuestros universos simbólicos, para construir conjuntamente los conocimientos que luego son transmitidos. Obviar a los estudiantes en este proceso de producción de conocimiento, es negar una de las partes fundamentales, en la que los docentes somos interpelados como tales y como compañeros de trabajo. Es esta la experiencia de un aprendizaje conjunto que llamamos "aprender-enseñar-aprender".

\section{Notas bibliográficas}

(1) Proyecto de Investigación en el marco del Programa Nacional de Incentivos "Escolarización / Disputas políticas: Etnografías de procesos educativos escolares en contextos sociales multisituados, 2015-2018".

Directora Stella Maris García (Código $11 \mathrm{~N}^{\circ} 789$ )

(2) La cátedra corresponde al tercer año de la carrera de Antropología y su planta docente está integrada por un profesor titular y un adjunto, un jefe de Trabajos 
Revista de la Escuela de Ciencias de la Educación, año 13, nRo. 12, vol. 2, julio a diciembre de 2017. Páginas 35-48. ISSN 1851-6297. ISSN 2362-3349 (EN LINEA). APRENDER HACIENDO. REFLEXIONES EN TORNO A LA FORMACIÓN COMO ANTROpólogos. Stella Maris Garcia, Griselda laura Aragón y luciana Pérez Clavero

Prácticos, tres Auxiliares docentes graduados, todos ellos rentados y tres auxiliares docentes alumnos ad-honorem. Se enuncian contenidos del programa 2012.

(3) Escenas narradas en base a las notas tomadas por las autoras en sus Diarios de Campo, Colonia Josefa, Valle Medio del Río Negro, Argentina (16 al 24 /Octubre de 2015).

(4) Monolito frente a la entrada del edificio con la siguiente leyenda: Don Marcelino González Vespa 9 de Agosto de 1943. Colonia Josefa perpetua la memoria de un colonizador ejemplo de virtud y de bondad.

(5) El Estatuto del Peón Rural fue un decreto del Poder Ejecutivo Nacional ( $N^{\circ} 28.169$, de 1944) dictado durante la presidencia de facto del general Edelmiro Farrell, para su aprobación por el coronel Juan Domingo Perón, quien se desempeñaba como Secretario de Trabajo y Previsión. Esta normativa fijó por primera vez, para todo el territorio de la república, condiciones de trabajo humanitarias para los asalariados rurales no transitorios, entre ellas: salarios mínimos, descanso dominical, vacaciones pagas, estabilidad, condiciones de higiene y alojamiento. Este decreto fue ratificado por la ley ómnibus $\mathrm{N}^{\circ} 12.921$ y reglamentado por el decreto $N^{\circ} 34.147$ del año 1949. Su sanción el 8 de octubre de 1944, es señalada como el comienzo de la protección legal del trabajador rural. Significó un visible cambio en las estancias, en muchas de las cuales se mantenían prácticas semiserviles y paternalistas heredadas de la época colonial.

(6) Los alumnos recién tendrán metodología de investigación en el 5to año de la carrera.

(7) Nos referimos a las celebraciones de aniversario de la colonia cada 12 de Octubre.

\section{Referencias Bibliográficas}

- Balandier, G. (1973). Teoría de la descolonización. Buenos Aires: Tiempo Contemporáneo.

- Bartolomé, M. (2006). Procesos interculturales Antropología política del pluralismo cultural en América Latina. México: Siglo XXI Editores.

- Barabas, A. (2006). Dones, dueños y santos: ensayo sobre religiones en Oaxaca. México: Editorial Porrúa - INAH.

- Berger, P. y Luckmann, T. (1976). La construcción social de la realidad.Buenos Aires: Amorrortu.

- Bourdieu, P.; Chamboredon J.C. y Passeron J. C. (1975). El oficio del sociólogo (Primera y segunda parte). México: Siglo XXI.

- Foucault, M. (1976). Las redes del poder. En: Barbarie No 4 - 5 (1981-2). Brasil: San Salvador de Bahía, pp. 23 - 39.

- Garbulsky, E. (2004). La Producción del Conocimiento Antropológico-Social en la Facultad de Filosofía y Letras de la Universidad Nacional del Litoral, entre 19561966. Vínculos y relaciones nacionales. En Cuadernos de Antropología Social $N^{\circ}$ 20, pp. 41- 60, Buenos Aires: FFyL - UBA.

- García, S. y Solari Paz, V. (2009). Investigar la escuela. Desafíos teóricometodológicos desde la Antropología. En: Tamagno, L. (Organizadora) (2009). Pueblos Indígenas: Interculturalidad, Colonialidad y Política. (pp 165-189). Buenos 
Aires: Editorial Biblos.

- Guber, R. (2001). La etnografía. Método, campo y reflexividad. Buenos Aires: Norma.

- Hammersley, M. y P. Atkinson. (1994). Etnografía. Métodos de investigación. Barcelona: Paidós Ibérica.

- Krotz, E. (1991). Viaje, trabajo de campo y conocimiento antropológico. Revista Alteridades, 1 (1). 50-57. México.

- Litwin, E. (2008). El oficio de enseñar. Condiciones y contextos. Buenos Aires: Paidós.

- Mauss, M. (2009). Ensayo sobre el don. España: Katz editores.

- Menegaz, A.; A. Mengascini, D.; García, M. P.; Arnedillo, A.; Sarutti, A.; Ottenheimer, A.C. (2003). Los viajes de campaña: su caracterización y valoración como espacio formativo en la Facultad de Ciencias Naturales y Museo (UNLP). Ponencia en el Congreso Latinoamericano de Educación Superior.

- Menéndez, E. (1972). Racismo, colonialismo y violencia científica. Revista Transformaciones. Buenos Aires: Centro Editor de América Latina.

- Ottenheimer, A. C. (2008). La creación de la licenciatura en Antropología en La Plata: un aporte a la historia de la enseñanza de la disciplina. Ponencia presentada al IX CAAS, Misiones. CD ISBN 978-950-579-103-3.

- Radcliffe-Brown, A. (1975). El método de la Antropología Social. Barcelona: Editorial Anagrana.

- Sarmiento, D. F. (1851). Facundo: Civilización y barbarie. Argentina: Claridad.

- Schaff, A. (1992). Historia y verdad. Capítulo I. (pp. 73 - 114). México: Grijalbo.

- Soprano, G. (2006). Continuidad y cambio en los estudios en etnología en poblaciones indígenas contemporáneas y comunidades folk en la Facultad de Ciencias Naturales y Museo de la Universidad Nacional de La Plata. Anuario de Estudios en Antropología Social. Centro de Antropología Social. Buenos Aires: IDES.

- Teruggi, M. (1988). Museo de La Plata 1888 - 1988. Una centuria de honra. Avellaneda: Fundación Museo de La Plata.

- Teves, L.; Remorini, C.; Morgante, G. y Leipus, M. (2008). 50 años de Antropología en el Museo de Ciencias Naturales: historia, desafíos y perspectivas. Ponencia presentada al IXCAAS, Misiones CD ISBN 978-950-579-103-3.

- Tamagno, L.; García, S. M.; Ibañez, M.; García, M. del C..; Alaniz, M.; Solari Paz, V. y Maidana, C. (2005). Testigos y protagonistas: un proceso de construcción de conocimiento conjunto con vecinos Qom. Una forma de hacer investigación y extensión universitaria. En REVISTA ARGENTINA DE SOCIOLOGÍA Año $3 \mathrm{~N}^{0} 5$, Buenos Aires, (pp. 2002-218). ISSN 1667-9261.

- Velázquez Galindo, Y. (2012). Transmisión cultural y construcción social de la persona nahua. ETNICEX Revista de ESTUDIOS Etnográficos, 4, pp. 82 - 97.

- Worsley, P. (1966). El tercer mundo. Madrid: Siglo. 